\title{
VI(VER), FILMAR, ENVIAR "trabalho" vigilante ou a biopolítica do amador no caso Virginia Tech
}

\author{
Gabriel Malinowski ${ }^{1}$
}

\begin{abstract}
Resumo: o pensamento desse ensaio é disparado por uma faceta do acontecimento que ficou conhecido nos mídia como o "massacre de Virginia Tech”. Trata-se do vídeo produzido pelo estudante Jamal Albarghouti no momento em que o estudante-atirador Cho Seung-hui fazia seus disparos contra alunos e professores. Nesse vídeo precário e imprevisto, mostrando a parte de fora do campus universitário, ouvem-se disparos de Cho. Em seguida, Jamal envia essas imagens e sons para o site da CNN, em uma sessão intitulada i-Report (eu-Repórter). Interessa-nos então questionar: por que esse estudante filma? Por que, espontaneamente, ele envia esse vídeo para a CNN? A fim de esboçar algumas repostas a essas questões, tratamos de repensar essa ação como uma forma de trabalho própria às sociedades da informação, que são perpassadas por forças biopolíticas de todo diversas das modernas sociedades industriais.
\end{abstract}

Palavras-chave: Biopolítica. Imagem. Vigilância. Jornalismo.

\begin{abstract}
The thought of this essay is triggered by a facet of the event which became known in the media as the "Virginia Tech massacre". This is the video produced by the student Jamal Albarghouti when the student-gunman Cho Seung-hui made his shots against students and teachers. In this precarious and unpredictable video, showing the outside of the campus, we can hear the shots of Cho. Then Jamal sends these pictures and sounds to the CNN website, in a session entitled i-Report. Why did Jamal take this video? Why, naturally, he sends the video to CNN? In order to outline some answers to these questions, we treat to rethink this action as a way of work in information societies, which are pervaded by new biopolitical forces.
\end{abstract}

Key-words: Biopolitcs. Image. Surveillance. Journalism.

A popularização de câmeras e filmadoras digitais nos fez entender muito rápido que as pessoas tinham a habilidade de não apenas escrever, mas também contar suas histórias com fotos e videos por meio de tecnologia que usamos diariamente.

Lila King, produtora do CNN.com e criadora do iReport

Faça do seu celular uma arma a favor da plena cidadania! Fotografe situações de cidadania exemplar como estas que estão aqui embaixo e envie para nós com um relato sobre o

\footnotetext{
${ }^{1}$ Mestre emComunicação pela UFF-RJ (2010). Professor dos cursos de Comunicação e de Artes Visuais do Centro Universitário de Barra Mansa-RJ. Email: gabrielmalinowski@gmail.com.
} 
flagra e a lição que você acha que pode tirar e passar adiante. Se aprovadas, você terá suas imagens divulgadas aqui nesta página e ainda receberá um certificado de Cidadão Exemplar (...).

Site A Voz do Cidadão

\section{Imagens de uma tragédia}

O massacre de Virginia Tech, nome dado pelos mídia ao caso do estudante que abriu fogo contra alunos e professores e, em seguida, se suicidou, pode render instigantes análises acerca do estatuto do sujeito contemporâneo que habita os mídia, em vários sentidos. Primeiramente, cabe lembrar que esse estudante-atirador, Cho Seung-hui, produziu e enviou um Manifesto Multimidia para a rede de televisão americana NBC antes de cometer os assassinatos. Além disso, é significativo o fato de a própria "aparição" da tragédia de Virginia Tech nos mídia ter se dado com imagens gravadas pelo aluno Jamal Albarghouti, no momento em que Cho fazia seus disparos. Muito bem ressignificadas pela $\mathrm{CNN}$, através de falas, caracteres e discursos, essas imagens mostram a parte de fora do campus. No vídeo, de pouco mais de um minuto, vê-se parte do campus universitário com alguns prédios em perspectiva, uma pequena movimentação de um grupo de pessoas, um veículo à direita e uma bicicleta à esquerda. De tempos em tempos, podemos ouvir os disparos que dimensionam a tragédia. Não se vê o atirador nem tampouco as vítimas. Entretanto, a incorporação de todos esses elementos ressalta um desejo de registro do "cinegrafista". O que torna o vídeo ainda mais intrigante é o fato de ele ter sido realizado numa situação limite para o estudante que o filmou. Pois, ao mesmo tempo em que realiza a experiência de estar no centro de um tiroteio, Jamal dispõe de um artefato que lhe permite registrar e compartilhar não só o acontecimento, mas essa própria experiência: seu correr solitário, seu silêncio perante o terrível.

Feito com uma câmera de telefone celular, o vídeo alcançou todo o mundo por se tratar das primeiras imagens da tragédia a serem divulgadas na mídia. Primeiramente pela Internet, no site do canal de televisão americano $C N N$, numa sessão intitulada Eu-repórter (iReport) e, a seguir, quase que simultaneamente, na mídia televisiva do canal. Afinal, por que esse estudante filma? Por que, espontaneamente, ele envia esse vídeo para a CNN? Sem querer responder ou encerrar de fato essas complexas questões, trataremos aqui de compor alguns argumentos que sugiram possíveis caminhos de resposta. Desse modo, interessa-nos menos chegar a conclusões deveras esclarecedoras do que buscar referências que nos ajude a 
pensar essa ação, de modo a indicar alguns sentidos e valores que, de maneira cotidiana, vão sendo caucionados e reproduzidos em nossas sociedades da informação.

O fato de esse estudante ter tido também seus quinze minutos de fama, concedendo entrevistas para vários jornais americanos, parece uma primeira pista a ser levada em consideração. Afinal, na moral do espetáculo, como já enfatizava Debord, “o que aparece é bom" (DEBORD, 1997, p.16-17). Como retribuição ao seu feito, o rosto desse estudante é também cooptado e vira uma espécie de tradutor das sensações da tragédia.

Por outro lado, autores como Antonio Negri e Michel Hardt argumentam que na contemporaneidade "a mão de obra industrial foi restringida e em seu lugar ganhou prioridade a mão de obra comunicativa, cooperativa e cordial" (NEGRI e HARDT, 2005, p.13). Entretanto, se se trata, efetivamente, dessa mão-de-obra, então o que estaria em jogo, em meio às práticas envolvendo essas produções amadoras, seria uma reconfiguração do estatuto do trabalho? Porém, na maioria das vezes, essa produção amadora não deveria ser entendida no sentido oposto, atuando mais no campo do lazer, da não obrigatoriedade, do quase (ou total) entretenimento?

\section{Trabalho, labor e lazer: a biopolítica do amador}

As formas de trabalho em sociedades de capitalismo liberal avançado, como já enfatizado por diversos sociólogos e filósofos, é uma dimensão da vida social que, inserida em um contexto tecnológico e político com arranjos diversos daqueles do início das sociedades industriais, vem adquirindo novos modelos, formas e vínculos. Richard Sennett, por exemplo, usa o termo flexibilidade (SENNETT, 2000) para tratar desses novos modos de trabalho que não estão mais ancorados na projeção de uma carreira, com uma identificação e confiança entre os pares. Antes, trata-se de uma forma de trabalho que privilegia a criatividade, a agilidade e independência do trabalhador, produzindo, com isso, novas espectativas, sentimentos e crenças. Claro que se trata, em Sennett, ainda do trabalho tal qual sua conceituação moderna.

Estendendo para outros campos esse cenário da força de trabalho, alentemos então uma hipótese ainda muito frágil: de que a produção dessas imagens amadoras (que são apropriadas pelos mídia, como nesse primeiro vídeo da tragédia apresentado pela CNN) integram um quadro amplo de reconfiguração das formas de utilização da força humana. Tratar-se-ia, nesse sentido, de um redirecionamento de sua função na sociedade. As práticas 
similares às do estudante que registra os tiros de Cho atuariam como uma mão-de-obra espetacular.

O trabalho, sendo entendido como a produção de objetos para a vida em sociedade, deve ser constantemente reavaliado. Em sociedades da informação, a imagem, como já enfatizado por Debord, torna-se também mercadoria, pois possui valor. Através dela, ou das informações que as ressignificam, os homens calculam seus dias, seus afazeres, suas concepções a respeito dos outros, rediscutem seu cotidiano - já que elas adentram a produção de sua realidade. Tanto é assim que casos como o de Virginia Tech sempre trazem à tona debates a respeito da violência, das armas de fogo, dos valores da juventude. Essa imagem produzida pelo estudante na parte de fora do campus funciona como peça introdutória para um manancial de outras imagens que, a partir dela, serão geradas pela grande mídia: imagens de entrevistas com parentes, com diretores, pedagogos, policiais. Assim, essa primeira imagem produzida pelo estudante deve ser vista como uma mercadoria que demandou certo trabalho em sua produção. Um corpo ativo a produziu e, em seguida, a encaminhou para os canais de distribuição. Esse mesmo corpo, que vivia o próprio incidente, parece obedecer a comandos novos, a modulações outras que vêm sendo caucionadas em sociedades da informação. Trata-se de uma forma de trabalho que possui novas formas de retribuição talvez com a moeda da visibilidade.

A distinção entre labor e trabalho enfatizada por Hannah Arendt, em $A$ condição humana, talvez possa deixar mais clara nossa proposição e nossas perspectivas. Arendt, repensando o conceito de vita activa (ou seja, as atividades do labor, do trabalho e da ação), aloca o labor como a atividade que corresponde ao processo biológico. Sendo assim, o labor, ou a condição humana do labor, seria a própria vida.

Em toda a revisão desse termo proposta pela autora, nota-se uma tentativa de investigar por que labor e trabalho, principalmente ao longo da modernidade, se entrelaçaram e se tornaram conceitos similares até mesmo para a filosofia política da época. Para a autora, o desprezo pelo labor na teoria antiga e sua glorificação na teoria da modernidade baseavamse, ambas, na atitude subjetiva ou na atividade do trabalhador, uma desconfiando de seu doloroso esforço e a outra louvando-lhe a produtividade. Na primeira, laborar significava ser escravizado pela necessidade, já que, pelo fato de serem sujeitos às necessidades da vida, os homens só podiam conquistar a liberdade subjugando outros homens. Assim, a degradação do escravo, por exemplo, era um rude golpe do destino. A era moderna, de modo oposto, passa a 
glorificar o trabalho como fonte de todos os valores. Funde-se, assim, o labor de nosso corpo com o trabalho de nossas mãos.

Como bem apontou George Agambem, a teoria de Arendt ganha importantes variações no pensamento foucaultiano, ainda que neste não haja nenhuma menção ao trabalho da autora. Para Foucault, o investimento na vida foi uma estratégia utilizada pelas sociedades capitalistas para o seu próprio funcionamento. Segundo Foucault, "por milênios o homem permaneceu o que era para Aristóteles: um animal vivente e, além disso, capaz de existência política; o homem moderno é um animal, em cuja política sua vida de ser vivente está em questão" (FOUCAULT, 1988, p.156). É a vida biológica que entra assim no centro dos investimentos, afim de produzir uma força de trabalho necessária. O trabalho se coaduna com estratégias biopolíticas, nas quais se formam um indivíduo com um corpo a ser laborado, uma população a ser preservada, uma identidade a ser constituída, bem como condições subjetivas para vivê-la e perpetuá-la. Sendo assim, a dimensão biológica, da vida, reflete-se na dimensão política. Na verdade é essa dimensão biopolítica, ou seja, do homem como ser vivente, que passa a ser solicitada através de um conjunto de fatores conexos, que Foucault soube tão bem desenvolver de forma paralela. Corpos dóceis e úteis passam a ser necessários para o sistema que se forma nesse jogo de forças, controlando, de um lado, a dimensão política dos indivíduos e, de outro, a produção necessária para o funcionamento desse sistema.

A análise que, não sem certa dificuldade, podemos delinear nas práticas envolvendo a captação de imagens, e sua respectiva publicação na Internet, parece fazer parte das complexas variações dessa docilidade e utilidade, mediante uma reconfiguração do próprio capitalismo. A apropriação da força e da ação humana se dá em novos contextos, nesses casos. As práticas envolvendo esses vídeos parecem ser uma das vias de atuação desse podersaber biopolítico nas demandas cognitivas atuais do ser vivente - enfatizando sua capacidade perceptiva e atencional para determinadas ações. Pode-se perceber também o quanto essa biopolítica é retroalimentada cada vez menos pelo Estado. Na lógica neoliberal, com a diminuição das intervenções do Estado, parece significativo notar como essas práticas também passam a ser fomentadas por entre relações de poder em mercados privados. O uso de aparelhos celulares talvez seja um bom exemplo, já que empresas privadas foram, praticamente desde o início, responsáveis pela difusão dessa tecnologia. Hoje, com esses aparelhos funcionando como dispositivos híbridos móveis de conexão multirredes (LEMOS, 2007), é interessante perceber como novas estratégias vão sendo a eles conformadas. O vídeo produzido pelo estudante Jamal deve ser inserido nessa relação, como resultado de uma gama 
de vertentes que possibilitam sua aparição e sua atuação no jogo societário. Trata-se de um empoderamento do sujeito que altera as práticas antes restritas à Indústria Cultural, com suas regras profissionais e suas vias de acesso.

Uma faceta dessas estratégias em curso pôde ser vista em uma recente publicidade do jornal $O$ Globo pelas ruas do Rio de Janeiro. Solicitando a participação dos moradores cidadãos, lia-se em algumas propagandas frases do tipo: Buraco na rua, fotografe! Engarrafamento, denuncie! Essa publicidade parece reforçar, de modo claro, aquilo que Deleuze observava na década de 80: que, nas sociedades de controle, nunca se pára de trabalhar, porque nunca se encerra nada. Em uma sociedade da informação, todos os corpos são aptos a portá-la, traduzi-la e propagá-la virtualmente. Calcada em um presente ubíquo, em um curioso "tempo real" - que produz um efeito de univocidade -, essa comunicação adquire grande inteligibilidade através de uma imagem qualquer, mediante essa pedagogia do olhar de nossos tempos. Talvez por isso o ligeiro sucesso de dispositivos como o Eu-repórter. Além disso, essa publicidade do jornal $O$ Globo parece conter um tom de mobilização geral, produzindo um sentimento policial em seus cidadãos - assim também como o anuncio do portal A Voz do Cidadão, com a frase "Faça do seu celular uma arma!"

Uma outra variação importante desse estado de coisas é o estatuto do jornalismo que, com seus espaços próprios, suas delimitações, suas instituições, enfrenta irrefreáveis embates e discussões a respeito de seu savoir-faire. O depoimento da produtora sênior do CNN.com e criadora do iReport evidencia como essa lógica amadora passa a adentrar nas próprias redações dos grandes jornais, interferindo, ainda que insidiosamente, na produção das notícias:

Tornou-se também parte da nossa rotina diária dentro da redação: toda manhã, quando editores de toda a empresa se juntam para discutir o que está sendo feito, o iReport é trazido à mesa. Discutimos a apuração de notícias nacionais, internacionais e passamos por cima do que está acontecendo no iReport. (KING, 2008)

Os recentes debates, nos cenários midiático e acadêmico, acerca do estatuto do jornalista e da notícia parece ser um sintoma dessas mutações. Vasta é a bibliografia que atesta essa "crise", como o recente livro do correspondente internacional da CBS Tom Fenton, Bad News: The decline of reporting, the bussiness of news, and the danger to us all ${ }^{2}$.

2 Más notícias: o declínio da reportagem, o negócio das notícias e o perigo para todos nós. 
Uma curiosa variação disso, no caso brasileiro, foi a recente e polêmica decisão do Supremo Tribunal Federal de descartar a obrigatoriedade do diploma de jornalismo para o exercício da profissão.

\section{Treinamento e contratação de cidadãos}

No início do filme Teorema, da década de 70, Pasolini constrói uma sequência que, para a época, talvez parecesse a visão de um comunista errante. Entretanto, hoje podemos lêla de uma maneira diversa, inserindo-a em uma pungente reflexão acerca das formas de trabalho e dos modos de vida em sociedades pós-industriais. A cena se passa em uma fábrica de um rico industrial de Milão. Trata-se de um alvoroço entre operários, diretores e jornalistas. Isso porque o rico industrial havia decidido dividir a empresa com seus empregados, tornando-os como que sócios. "- Um ato isolado ou uma tendência geral do mundo moderno? Considerando como um símbolo de um novo curso de poder, este não é um primeiro passo para a transformação de toda a humanidade em pequeno burguesa?" - pergunta um jornalista.

A validade de se pensar nessa produção amadora como uma nova forma de trabalho, principalmente quando há uma solicitação dos próprios meios de comunicação para tal prática, parece ser ainda a avaliação dos componentes do sistema de produção de bens, que, por sua vez, produzem novos artefatos com valores que vão sendo capitalizados de acordo com uma variada rede de situações. O conhecido vídeo "erótico" em que a apresentadora de televisão Daniela Ciccareli está na praia com seu namorado e o vídeo da morte de Saddam Huissein são exemplos de imagens amadoras, desautorizadas, sem autoria, mas que viraram “imagens-acontecimentos" do ano de 2006 (BRASIL e MIGLIORIN, 2006). Esses dois exemplos, segundo André Brasil e Cézar Migliorin, apontam para uma nova ética nas imagens, dada a forma com que foram produzidas, difundidas e utilizadas. E essa nova ética das imagens parece refletir, por sua vez, insistentemente, na própria relação com esses novos cinegrafistas.

Ora, tanto nesses dois casos quanto na maioria desses vídeos amadores flagrantes, não há nenhum vínculo formalmente fechado e nenhum contrato assinado em termos burocráticos. As imagens aí, com efeito, deslizam como dados, e esses dados adquirem virtualidades que implodem as formas modernas de autoria e de responsabilidade. Esse trabalhador, munido 
desse ainda ardiloso repertório ético-estético, tem apoio em uma intrincada relação que abarca, dentre outras, forças subjetivas (a possibilidade de ver sem ser visto, por exemplo) e midiáticas (a existência de canais de distribuição, por exemplo).

Há ainda outros fatores que contribuem para a construção desse tipo de trabalhador. Para alguns autores da "pós-modernidade", a troca de "identidades" se processa, no compasso da sociedade do espetáculo, na própria superfície dos corpos, nos cabelos, nas roupas, nos acessórios e no "estilo" de cada um. Em outras palavras, as questões identitárias são investidas, mais e mais, em um regime da aparência, que propõe novos tons e matizes, em sua dinâmica com a interioridade psicológica. Talvez seja o próprio estatuto da identidade que, nesse caso, passe por modificações. O sociólogo/filósofo Zigmunt Bauman, por exemplo, a respeito da conformação de identidade contemporânea, traçou o seguinte diagnóstico:

Selecionar os meios necessários para conseguir uma identidade alternativa de sua escolha não é mais um problema (isto é, se você tem dinheiro suficiente para adquirir a parafernália obrigatória). Está à sua espera nas lojas um traje que vai transformá-lo imediatamente no personagem que você quer ser, quer ser visto sendo e quer ser reconhecido como tal. (BAUMAN, 2005, p. 91)

Aqui, exemplarmente, a identidade, a relação do sujeito com seu self, não é vista em meio a uma elaboração interna e expressão externa. Produzir uma identidade, com novos estilos de vida, não passa, necessariamente, pelas tortuosas profundezas da interioridade psicológica ou por um trânsito entre o interior e o exterior. Para Bauman, a produção de um "ser outro" passa menos por uma elaboração interna do que por uma escolha de objetos que possam dizer quem você é, do que você gosta e em que grupo você se encaixa (todos eles, aliás, à disposição no mercado).

Repensando as questões de identidade no contexto de nossa segunda cena, cabe lembrar que o próprio trabalho (labor), desde a modernidade, participa ativamente da construção subjetiva. Uma das bases de formação daquele que se é parece estar relacionada ao papel social que se exerce. Não é à toa que, em tempos de trabalho flexível, como aponta Sennett, as identificações tendam a ficar menos rígidas, a assumir novas dinâmicas. Assim, nesse trabalho espetacular, uma vez configurada uma identidade de produtor de imagens, de cinegrafista amador, parece viável e legítimo, no campo da existência, produzir notícias, 
produzir imagens de si, produzir uma imagem qualquer através dos dispositivos multimidiáticos à disposição no mercado.

Daí, pensarmos, em seguida, nas implicações desse ato produtor, dessa ação. Para Hannah Arendt, a faculdade da ação seria a faculdade propriamente política, aquela que atuaria no campo do imprevisível e da pluralidade. Na ação de se produzir uma imagem para esses novos canais de distribuição estaríamos tratando de que política?

A ação do estudante Jamal parece contar com um puro registro, que é inserido como um "efeito de real" e passa a atuar como uma ilustração ao discurso jornalístico da grande mídia. O vídeo do estudante não fala por si só. A imagem não possui tal força. Nela, nota-se apenas uma tentativa de tornar visível uma situação problemática. O papel desse estudante parece ser apenas esse: capturar uma imagem de forma apática, o mais próximo do "real", sem interferir no acontecimento, sem propor nenhum enunciado além da simples aparência do que é dado a ver. Trata-se da utilização dos meios técnicos de registro em favor de um olhar desencarnado, um olhar que quer apenas capturar esse real primeiro que lhe é oferecido. Seu papel é registrar tudo como uma câmera de vigilância, ainda que as imagens apontem para as tensões corporais do momento (como na parte final do vídeo, quando Jamal se joga no chão e encerra a filmagem). O garoto engendra, literalmente, uma câmera subjetiva ${ }^{3}$ que leva essa estilística ao paroxismo. Parece haver, nesse caso específico, uma ação colaborativa.

As relações de forças que possibilitam algumas modulações dessas ações, as quais parecem, muitas vezes, desprovidas de uma força singular ou plural, são diversas. Gilles Deleuze lembrava, por exemplo, em meados da década de 80, que assistir a um programa de televisão no estúdio era um dos espetáculos mais apreciados da época. A questão, para Deleuze, com esse espectador passado aos bastidores, não era mais de beleza nem de pensamento, mas de "estar em contato com a técnica, tocar a técnica" (DELEUZE, 1992, p.93). Também em um curioso depoimento da produtora da CNN Lila King, podemos notar, de maneira clara, um discurso acerca de uma certa política de treinamento que o iReport enseja. A resposta de King parece tão rentável para se avaliar a dimensão estética desse treinamento que vale aqui sua reprodução integral. A pergunta do jornalista, a partir da qual a resposta é proferida, versava sobre os possíveis problemas com plágio ou informações não corretas enfrentados pelo iReport. Daí, começa King:

\footnotetext{
3 Nomenclatura de uma técnica amplamente utilizada no cinema. Nela, simula-se a visão do personagem através do ponto de vista da câmera.
} 
Para ser honesta, não é algo que temos muitos problemas e não é surpresa para mim a qualidade média do conteúdo publicado no iReport. Acontece muito raramente descobrir durante a seleção que determinada história tem problemas. O que mais acontece durante a verificação é percebermos que a pessoa não teve treinamento profissional e pode ter sido ingênua na redação ou na edição. Aconteceu recentemente com um usuário na Flórida que tirou fotos de uma tempestade e aplicou mais contraste no PhotoShop, que tinha acabado de comprar. Percebemos que havia algo não real na imagem e um dos produtores ligou para ele, que admitiu que tinha colocado mais contraste na foto enquanto aprendia a mexer no programa. Ele mandou a versão original e nós explicamos que no fotojornalismo não se faz edições deste tipo, já que a imagem tem que estar o mais próximo possível da realidade. No fim, a técnica de jornalismo do leitor melhorou. (KING, 2007)

Claro que, não devemos pensar que as Organizações Globo, a CNN ou o YouTube sejam causas determinantes dessa conjuntura, dessas ações. Ainda que essas empresas estejam inseridas vertiginosamente nesse contexto, parece mais coerente pensá-las como mecanismos que alimentam a própria lógica discursiva capitalística de nossos tempos. Entretanto, não há como negar que essas empresas tendem a homogenizar suas medidas com base em seus limites discursivos, capturando, selecionando e controlando todos os sinais que emitem. $\mathrm{O}$ discurso de King parece caminhar nessa direção, "educando" os colaboradores e suas imagens com os significantes jornalísticos.

\section{Vigilância e espetáculo}

A possível vigilância das ações que vimos até aqui deve ser percebida como variante de um processo mais amplo. Trata-se de uma relação com o outro que possui raízes na formação das sociedades modernas. A vigilância está ligada a um desejo das instituições modernas de administrar e racionalizar suas operações, tornando-as eficientes e ágeis. Essa lógica parece se manter até nossos dias, ainda que ela se faça, agora, revestida de novas estratégias, novos modelos, novas arquiteturas. As imagens amadoras participam dessa reordenação das formas de olhar, que implode a moderna dialética dentro/fora. Contudo, deve-se nuançar essa afirmação, uma vez que essas imagens amadoras, em boa parte dos casos, não estão, necessária ou diretamente, voltadas para o exercício da vigilância. Como argumenta Fernanda Bruno: 
[Essas imagens] participam ativamente da construção de um regime escópico sobre a cidade e seus corpos que se passa não tanto nos circuitos de controle, mas sim nos circuitos de prazer, entretenimento e voyeurismo, onde vigoram uma atenção vigilante e a captura do flagrante. (BRUNO, 2007)

Um exemplo curioso dessa relação parece ser os concertos de música, nos quais os espectadores assistem grande parte do concerto com os olhos nos visores de seus aparelhos celulares ou de suas câmeras digitais. Não se trata aí, exclusivamente, de uma vigilância, mas de um controle daquilo que se dá a ver, de uma atenção vigilante. Caso haja algum descuido do artista que se apresenta - como um tombo - ele não será perdoado e, certamente, será um dos vídeos mais vistos durante a semana em sites de compartilhamento de imagens.

Em outro contexto, sentido e valoração atuou, por exemplo, o conhecido vídeo postado no YouTube Me dá meu chip Pedro!. Essas imagens renderam até mesmo uma reportagem no programa Fantástico, da Rede Globo, com o instantaneamente famoso Pedro que, ironicamente, não chega a aparecer nas imagens que o popularizaram na Internet. Do alto de um apartamento, o cinegrafista filma a casa do vizinho Pedro com uma mulher à porta que grita em bom tom: “- Pedro, cadê meu chip!”. Em certo momento do vídeo o cinegrafista anuncia, com um assovio, que ele a observa. Ela responde com palavras de baixo escalão e continua em busca de seu chip. A relação cinegrafista/vigiada é curiosa: ele se diverte, ri da situação, promove seus assovios, faz comentários. Tudo isso sem se mostrar nem tampouco alterar a postura da moça. Ele se diverte com sua produção: desvia em alguns momentos a câmera da mulher (possivelmente se escondendo de seu olhar), comenta que a moça quer muito o chip. Nota-se assim que vigilância e espetáculo se entrelaçam e assumem, ambas, funções e hibridismos que os distanciam de suas conceituações modernas.

Essa vigilância arraigada à cultura do espetáculo altera até mesmo o mais clássico dos dispositivos de vigilância. A prisão assume diversas variações nesse cenário cultural, nessas sociedades de controle. No Brasil já é notória a capacidade de presos comandarem ações de dentro dos presídios, através do uso de telefones celulares. Os países de capitalismo liberal avançado investem em novas tecnologias de controle, como chips, câmeras de vigilância, etc. Além disso, as neurociências já propõem estudos de prevenção a ações criminosas. Nesse caso, a predisposição criminosa do sujeito seria detectada em seu DNA. A partir daí, tomarse-iam medidas preventivas, como o deslocamento desse sujeito para outros ambientes, outras comunidades, nos quais sua "predisposição" criminosa não pudesse se expressar. 
Podemos observar ainda apropriações desse dispositivo prisão no âmbito das representações audiovisuais. No cinema, um bom exemplo é o documentário O prisioneiro da grade de ferro: auto-retratos, de Paulo Sacramento, que torna visível os condenados por um familiar modelo narrativo: dando câmeras aos próprios presos. Trata-se de condenados que não devem ser excluídos do campo do visível, tampouco do campo produtivo das imagens. Em $O$ prisioneiro... os próprios detentos são postos a trabalhar, mas não mais prestando serviços na cozinha. Após algumas aulas de como operar as câmeras, o olhar do condenado é posto a favor da produção de um olhar mais autêntico para o filme. Produz-se, assim, um efeito de condenado, como se pelas mãos daqueles que ali vivem conseguíssemos atingir uma verdade mais íntima acerca de suas vidas.

Um outro exemplo instigante são as constantes aparições no YouTube dos vídeos dos prisioneiros de Cebu, nas Filipinas. A repercussão desses vídeos é tanta que habitualmente eles são comentados em conceituados telejornais de todo o mundo. Ao contrário do documentário brasileiro citado, não há aproximação ou singularização dos detentos. $\mathrm{O}$ interesse está em demonstrar a disciplina convertida em passos banais e sincronizados, em uma espécie de dança de programa de auditório. Do alto do pátio, alguém (talvez um preso) filma a disciplina daqueles detentos. A câmera faz algumas aproximações, mas nunca no sentido de destacar qualquer sujeito. A massa uniforme, tal qual uma parada militar, reconfigurada em uma aula de ginástica com grandes macacões alaranjados, dança pelo espaço de um pátio gigantesco. Geralmente, são conhecidas músicas americanas que embalam seus passos, como a recente Thriller, de Michel Jackson, encenada em homenagem à morte do cantor.

Lembremos, por fim, de um recente caso ocorrido em uma universidade brasileira que se instala entre a escola e a prisão. Trata-se dos vídeos produzidos pelos alunos da Uniban no momento em que Geyse, uma aluna do curso de Direito, era expulsa por estar trajando um vestido muito curto. O que temos nesse caso é um outro exemplo dessa lógica que mistura vigilância, voyerismo e prazer. Atrelado a isso, o coro dos alunos, acusando a estudante de "puta", integra uma espécie de punição espetacular. Na maioria dos vídeos produzidos pelos alunos ao longo do corredor que Geyse percorre, mostra-se ela de jaleco, resignada, rebaixada, e sendo escoltada por policiais. O celular e as câmeras tornam-se, efetivamente, uma arma, que fere e humilha pelo espetáculo. A estudante com um jaleco branco, que esconde seus trajes "impróprios", é a punição representada no vídeo. Os xingamentos graves, feitos em sua maioria por homens, reafirmam o local do sexo, das identidades e das aparências. As imagens atestam um controle daquele espaço pelos próprios alunos. Para 
aqueles que gritam (e filmam), a escola não se confunde com o prostíbulo. As imagens são como provas e ameaças, são os instrumentos desse policiamento espetacular. As ações de filmar e postar essas imagens atuam como uma força complementar à ação policial.

Há que se notar também que essa a humilhação espetacular assume uma dinâmica paradoxal. Isso porque a aluna da Uniban, dias após ter sua imagem no incidente divulgada em sites de relacionamento, se tornava uma personalidade, concedendo entrevistas a diversos programas de televisão. Essa oportunidade Geyse certamente aproveitará. Assim, quem sabe, no futuro, talvez possa se tornar uma apresentadora famosa e namorar em praias alhures, perante olhos de tantos outros "trabalhadores" vigilantes. Nesse caso, iríamos reunir, de uma ponta a outra, duas faces de uma mesma imagem.

\section{Referências bibliográficas}

AGAMBEN, Giorgio. Homo sacer: o poder soberano e a vida nua. Belo Horizonte: Editora UFMG, 2002.

ARENDT, Hannah. A condição humana. Rio de Janeiro: Forense Universitária, 2008.

BAUMAN, Zygmunt. Identidade: entrevista a Benetto Vecchi. Rio de Janeiro: Jorge Zahar Ed., 2005.

BRASIL, André e MIGLIORIN, Cézar. Saddam e Cicarelli: nossas imagens. Revista Cinética. Disponível em: < $\underline{\text { http://www.revistacinetica.com.br/saddamcicarelli.htm>. }}$

BRUNO, Fernanda. Estética do flagrante: controle e prazer nos dispositivos de vigilância contemporâneos. Dossiê estéticas da biopolítica, 2007. Disponível em: $<$ http://www.revistacinetica.com.br/cep/fernanda_bruno.htm $>$.

DEBORD, Guy. A sociedade do espetáculo. Rio de Janeiro: Contraponto, 1997.

DELEUZE, Gilles. Conversações. São Paulo: Ed. 34, 1992.

FOUCAULT, Michel. História da sexualidade I: a vontade de saber. Rio de Janeiro: Graal, 1988

"Le sujet et le pouvoir" In: Dits et Écrits II (1976-1988), Paris:

Gallimard, 2001.

KING, Lila. Lila King detalha impacto da web no jornalismo da CNN: Site FSB Comunicações, 2007. Entrevista concedida a Guilherme Felitti. Disponível em: $<$ http://www.fsb.com.br/index.php?conteudo=by_mercado\&id=25 $>$. 
LEMOS, André. Comunicação e práticas sociais no espaço urbano: as características dos Dispositivos Híbridos Móveis de Conexão Multirredes (DHMCM). Revista Comunicação, Mídia e Consumo, São Paulo, v.4, n.10, p.23-40, jul 2007.

NEGRI, Antonio e HARDT, Michel. Império. Rio de Janeiro: Record, 2005.

SENNETT, Richard. A corrosão do caráter: as consequências pessoais do trabalho no novo capitalismo. Rio de Janeiro: Record, 2000. 